\title{
Employers and Qualifications
}

\section{John Oxenham}

The central questions of the research summarised here were why and how employers in the modern sector use educational qualifications, first, to recruit (ie to delimit the pool of people eligible for particular employment), and then actually to select employees. ${ }^{1}$

The research was restricted to employers in large organisations: government departments, state corporations, private enterprises (both local and multinational), with more than 25 employees. The employees were selected mainly from nonmanual administrative groups: clerks, managers, salesmen and the like.

The studies were carried out in the capital cities of Ghana (1976), Mexico (1975), and Sri Lanka (1975). The sizes and distributions of the samples are set out below (but are not explained here): to indicate with fair accuracy the behaviour of all state agencies. Second, in each country the sample employers showed close consensus on a number of points. Since there was no evidence that they constituted a waywardly biased group, they can be taken to indicate the broad lines of thinking among a good many employers in the modern sector.

\section{Common Points}

Minimum educational qualifications

All our 70 employers laid down minimum education qualifications (MEQLs) for all those nonmanual posts which were open to young people with little or no work experience. Differences in colonial experience or strategies of development pursued since the attainment of political independence, made no difference here. In addition,

\begin{tabular}{lcccc}
\hline & $\begin{array}{c}\text { Ghana } \\
(\text { Accra })\end{array}$ & $\begin{array}{c}\text { Mexico } \\
\text { (Mexico City) }\end{array}$ & $\begin{array}{c}\text { Sri Lanka } \\
(\text { Colombo) }\end{array}$ & Total \\
Government departments & 7 & 3 & 0 & 10 \\
State corporations & 6 & 4 & 8 & 18 \\
Private-local & 6 & 15 & 7 & 28 \\
Private-multinational & 0 & 11 & 3 & 14 \\
Totals & 19 & 33 & 18 & 70 \\
\hline
\end{tabular}

None of the three samples was either large enough or so composed as to be strictly representative of the total sector of nonmanual wage and salary employment in the respective country. Nevertheless, the findings of the research deserve more than casual consideration on two grounds. First, in all three countries, the state plays a large role in modern employment. Since the departments and corporations of the state cannot develop widely eccentric personnel policies, the agencies included in our samples can be expected

1 Fuller accounts are given in two of the project's research reports, Brooke et al [1978] and Deraniyagala et al [1978]. The third report [Agyeman et al] is forthcoming. all 70 had constructed schedules of correspondence between jobs, salaries and educational qualifications: the higher the job is ranked in an organisation, the higher the initial salary it attracts and the higher the qualification it tends to require. At the same time, in all 70 organisations, people doing an identical job under one supervisor had various qualifications. Indeed, they could differ by as much as eight years of schooling. That is, although there are MEQLs, they are neither standard nor fixed.

\section{Raising educational qualifications}

Not surprisingly, substantial proportions of our employers acknowledged that the MEQLs for 
particular jobs had been rising over the previous 10 years. Their perception was confirmed in Ghana and Mexico by studies of job vacancies advertised in newspapers over 20 years, from 1955 to 1975. However, explanations for the escalation differed between countries and will be discussed later. In all three countries, primary or basic education is no longer used as a qualification. In Mexico, nine years of schooling are desirable even for an office cleaner; in Ghana, 10 years and in Sri Lanka 12 years of schooling are insufficient to guarantee even menial employment. $^{2}$

Determining minimum educational qualifications The fact that MEQLs are laid down for every job, coupled with the fact that MEQLs for similar, even identical, jobs vary both between employers and for one employer over time, makes a third fact also unsurprising. Not one of the 70 employers had ever tried systematically to match the functions of a particular job with the competences generally developed by a particular level of schooling. One employer in Mexico said that the firm first assessed the job, decided the maximum and minimum salaries which should be offered, and only then wondered what kind of educational qualifications were currently obtainable for that kind of price.

To be sure, 10 employers-again Mexicansdid use various methods of job analysis or job assessment, in which some stab was made at estimating how much schooling of what kind might be appropriate for the job. Even so, these estimates were substantiated not by any close examination of the matter, but rather by impressions, rules of thumb and "what the market offers'. Even in cases of technical jobs, where MEQLs have to be relatively specific, employers were unable to say convincingly why they demanded a technical degree earned through three or four years of study, rather than a technical diploma which required two years. In Mexico, a couple of employers even preferred university students who had not yet graduated, over diplomates from polytechnics. At the same time, they refrained from claiming that the former were any more knowledgeable or efficient.

\section{Preference for the more schooled}

The escalation of qualifications suggests that the 70 employers tend to prefer to select more

\footnotetext{
2 In Mexico, perhaps 35 per cent of an age cohort take more than 6 years of school; in Ghana, the 10 year Elementary School Course is completed by fewer than half an age cohort; while in Sri Lanka about half a cohort manage to graduate with an 11 or 12 year certificate.
}

schooled rather than less schooled personnel. This is indeed so. However, few of the employers could articulate why. In particular, there was scarcely a hint that those with more schooling tended to be more productive. The reasons advanced had more to do with qualities such as greater intelligence, superior capacity to learn, speed, accuracy, competence with written language and numbers or more systematic ways of thinking and working. (The latter largely unmentioned qualities are of course those to be expected from schooling in general. The others, frequently stressed, are more the products of upbringing and perhaps special schooling-in other words, of social background.)

Nevertheless, it has to be noted that the preference is not absolute. People with only the MEQLs still succeed in getting themselves selected in the face of competition from others with more than the MEQLs - although to be sure they do seem to be minorities. When all other things are equal, the 70 employers tend to opt for those with more education. But when candidates with only the MEQLs can offer something which their rivals cannot, they can still land a job. (Indeed, in Ghana, a few cases were found where people with less than the MEQLs had been hired. No explanation could be elicited.)

Also, although no employer set maximum qualifications, there was an evident reluctance to take people with much more than the MEQLs. The reasons given are as might be expected: the heavily overqualified are said to have difficulty in working with less qualified colleagues; they tend to be importunate for accelerated promotion; they are on the constant lookout for better jobs elsewhere; and, in Mexico, they are regarded as disoriented and deficient in appropriate motivation.

The limits of promotion by merit

In all three countries, it was once possible, at least in popular belief, for a person to rise from humble beginnings to the topmost positions by sheer excellent performance. All three groups of employers conceded that now such a process is less and less likely to occur. Performance on a job must be supplemented by the requisite educational qualifications. In Sri Lanka, the state employers have been pressured by the trades unions to accept that a person within an organisation being considered for promotion to a superior post, may have slightly lower qualifications than those which must be offered by a candidate from outside. In Mexico, on the other hand, the 'professionalisation' of occupations demands that the upper posts be held only by those with full 'professional' qualifications. Unless 
a person is willing to accumulate the appropriate diplomas along with appropriate experience, $s /$ he must be willing to forgo the commanding heights of his profession.

\section{Social responsibility}

Despite an earlier hint of social obligation, the employers use an egocentric rationality in determining what qualifications to demand for a job. They would all acknowledge that raising qualifications, either by simply hiring people with more than the MEQLs advertised, or by actually advertising for higher MEQLs, probably would result in raising demand for higher schooling. They would even accept the possibility of a secondary repercussion, that of depriving primary or basic education of the wherewithall to achieve universality-a proclaimed goal of all three states -and to improve its quality and efficiency. Yet the fact is that these 70 employers-even the government agencies-had never considered the matter in these terms. They had responded to it in the light only of their own interests and convenience.

They might counter an accusation of social irresponsibility by asking what alternative was open to them, though none of them had in fact contemplated alternatives. In Mexico particularly, questions on what employers might do if educational qualifications were not available, were rebuffed and labelled so hypothetical as to be not worth thinking about. Some agencies have indeed adopted aptitude tests and refined their selection procedures in detail. Even so, these measures are only supplements to educational prerequisites, not substitutes for them. Further, they have been adopted without proper testing, validation or even serious adaptation. In effect, the employers have been content to rely on the scholastic qualification as the major means of delimiting who shall and shall not be eligible to work in the modern sector. Whatever ill effects might flow from this reliance are, in their eyes, not their business, but the concern of the government or some part of the government which does not include themselves.

\section{Points of Difference}

\section{Patronage and politics}

Relationships between patron and client have been and continue to be a powerful fact of political and economic life in Mexico. The government agencies and most of the private employers in the Mexican group acknowledged this. The former, particularly, are used for fostering and cementing political alliances, and are independent of any centralised body in their standards of recruitment and remuneration. Of the private bodies, two openly stated that they recruited exclusively from among the relatives and friends of those already associated with the firms. On the other hand, forces are at work to change this tradition. President Echeverría introduced in 1971 an Administrative Reform which required all government agencies to set up bureaux to rationalise personnel selection and promotion. Although not totally effective, the power of these bureaux to mitigate the element of patronage seems to be growing steadily.

Among the private firms, the changes have proceeded faster, apparently partially because of the influence of American multinational companies. The recent trend is decidedly towards reducing the role of patronage and strengthening what might be called 'objective selection'.

Ghana and Sri Lanka were both British colonies and inherited very similar patterns of employment in both the public and private corporate sectors. Central Public Service Commissions controlled the conditions and terms of service. Educational qualifications, examinations and other relatively impersonal criteria governed access to the civil, teaching, police, military and other services. This tradition has continued, but apparently not without some dilution. In Sri Lanka, for instance, obtaining a letter of recommendation from a Member of Parliament has had to be institutionalised as an additional condition for securing employment with public agencies. In Ghana, there are unsubstantiated rumours that influence and bribes are becoming more powerful as conditions of access to public jobs. The very fact of the rumours indicates some loss of confidence in the objectivity of the implementation of standard procedures.

What makes it possible for Mexico to move towards greater impersonalisation or bureaucratisation and what is it that seems to loosen the hold which Ghana and Sri Lanka have long had on bureaucratisation? Our research did not address these questions. Nevertheless, we may hypothesise that the short answer to both would be the state of the economy, coupled with the expansion of schools and universities. Mexico had, at least up till 1975, enjoyed a relatively high and steady rate of economic growth, accompanied by a lower, but still steady expansion of modern sector employment. Although the output from the schools and universities increased faster than modern sector employment-so that qualification escalation could occur-the differ- 
ence was still small enough to permit some movement towards impersonal methods of personnel selection. In contrast, neither Ghana nor Sri Lanka has achieved comparable rates of growth in the economy or in modern sector employment, but both have expanded their school enrolments hugely. Hence, competition for what jobs were available presumably heightened, and with the heightening the temptations to cheat doubtless grew less resistible.

\section{Selection by social group}

An attenuated form of patronage is discrimination by social group. This denotes a tendency to apportion jobs of certain categories to people of certain socioeconomic backgrounds; or, in less sterilised terms, to keep the least remunerative jobs for the poorer sections of the population, and the more influential, better paid jobs for the richer. In some contexts, ethnic considerations may be mixed with socioeconomic: persons who are both poor and of a given ethnic group are more likely to have more difficulty in obtaining employment than those who are only poor. Elsewhere, of course, ethnic affiliations may on the contrary be positively useful for attracting preferential consideration for employment.

In this connection, the distinction in all three countries between those who draw salaries and those who earn wages, or between those who are casual employees and those on a permanent and pensionable footing, would seem to favour the existence of social selection because of two collaborating forces. On the one hand, those already in salaried employment would presumably work to help their children and other relatives secure similar employment. On the other hand, employers might well feel that young people from salaried backgrounds would be more apt to make good employees themselves, and hence favour them. In practice, however, the Mexican employers seem to stand apart from the Ghanaian and Ceylonese.

The former call their salariat, confidence employees-empleados de confianza-and expect considerable loyalty from them, unlike their other, often unionised, employees. The Mexican employers openly prefer to recruit confidence personnel from what might broadly be called the middle classes. Neither the Ghanaian nor the Ceylonese employers seem concerned with such considerations. They acknowledge that applicants from a number of well known schools may have an advantage, but argue that it is the ascertained quality of education which makes the difference, not the social provenance. Again, an obvious hypothesis obtrudes-that the Ghanaian and Ceylonese employers owe their common view on this point to their common colonial experience. The two states otherwise have the kinds of history and social structure which might suggest a certain strength for social or tribal considerations in the distribution of quasi-privileged employment. In one respect, they suffered from the British operating - at least in the major period of colonial rule - a racial criterion for selection to the most influential jobs. Yet, in another respect, they saw the British operating substantially meritocratic criteria, both in selecting British personnel and in selecting local personnel for whatever jobs were opened to local candidature. The reaction against the racial criterion coupled with the apparent fairness and effectiveness of the meritocratic criteria seems to have fostered the adoption -at least overtly-of the principle that social background should have no role in occupational selection. (Mexico had, of course, taken its independence from Spain long before the British had even taken any steps to rationalise selection to their colonial services.)

Four more points of difference between, on the one side, Ghana and Sri Lanka, and on the other, Mexico seem to owe their origins to the difference of colonial experience.

\section{Internal labour markets}

First, in both Ghana and Sri Lanka, among both the private and state employers, hiring a young person for a permanent career is common. A clerk, for instance, might rise to become a senior executive officer-although, as noted earlier, he would not be expected to rise much higher without higher qualifications. 'Career development' is an accepted concept and the paths for development are clearly laid down. A young person enters employment at a certain point on a salary scale and can confidently expect to move up the scale with virtually automatic annual increments of salary. Should his performance merit it or should he improve his paper qualifications-and provided an appropriate vacancy is available-he miaht get himself shifted to a superior scale. If the shift necessitates more paper qualifications, he might find himself having to compete with outsiders. Even so, in both Ghana and Sri Lanka, there is a presumption of preference for the insider. As noted above, Ceylonese insiders may not need to show as high paper qualifications as are demanded from outsiders.

The existence of such internal labour markets, combined with the extreme scarcity of employ. ment in the modern sector, has induced people 
with superior qualifications to accept inferior posts in the hope of gaining an edge in the competition for superior posts. (The relative scarcity of employment and, hence, the extent of this practice is greater in Sri Lanka than in Ghana.) An effect of this development will be to entrench even further the necessity for enhancing paper qualifications. For, in the event of competition between insiders for a superior post, an employer's choice is eased and is less disputable if some of the contenders display superior qualifications.

Just under half of the Mexican employers, in contrast, thought in terms of career development. The government agencies were largely precluded from doing so, simply because employment within them is so dependent on political fortune. (Still, if the Echeverria Administrative Reforms of 1971 do take root, the situation may change.) With others, an appointment to a confidence post is simply that. Progression and promotion may or may not occur. Indeed, people are almost expected to seek promotion by moving to other employers. Insiders are of course welcome to compete for such superior vacancies as may occur, but they seem to receive no preferential consideration.

Yet the notion of internal labour markets has begun to take hold, although only since the late 1960s. It seems again to be due to external influences, notably the patterns set by multinational firms. On the other hand, of the 33 employers studied, only two have gone so far as to elaborate fully what might be called career schemes. And, it can be noted, even a scheme for salesmen stipulated a degree for promotion to sales manager. (The nature of the degree will be discussed later.)

\section{Readiness to train new entrants}

The second point is associated with the first. If employers are willing to think in terms of careers for employees, they are likely to be willing also to provide guidance or training for induction, improvement and promotion, and hence to be accessible to inexperienced young entrants. That is, they accept the costs of instruction and learning as part of the cost of organisational health. On the other hand, if they regard employees almost exclusively in the light of the job to be done, they are apt to want the costs of learning to be borne either by the employee himself or by some other agency. This broad dichotomy proved largely valid in the three groups of employers.
The Ghanaians and Ceylonese without exception accommodated inexperienced but appropriately qualified entrants at a number of levels, and similarly organised periodic training for their employees. In contrast, most of the Mexicans required that their recruits have some previous experience, simply because they felt it was not their place to train people. They wanted work and it was up to their employees to know the work before applying for it. The conundrum that immediately presents itself is, how are people to learn to work, if they are expected to have worked before starting work? How can new entrants possibly enter? The answer comes in two parts, the first of which is to do with the meaning of work experience, while the second concerns the content of education.

The idea of pre-work experience is possible only because of another well established idea, namely that it is possible and indeed commendable to maintain a wholly satisfactory course of study as well as earn at least part of a living at the same time. Young people who devote themselves exclusively to study are not favoured. This notion entails one of two options. One can either go for full time work and part time study, or-on the North American pattern of working a way through college - for full time study and part time work. Mexico's employment and educational systems are geared for either option. The larger, better paying, more sought-after employers can insist on full time work combined with part time study, whereas the smaller employers are willing to accept part time work from inexperienced and underqualified employees in exchange for low wages and the opportunity for full time study. By this means, young people can accumulate experience, skills and paper qualifications to launch them towards the more affluent employers, who interpret work experience broadly. They seem to be less concerned with specific skills than with a fairly focused orientation to the types of work on offer, to habits of regular work and to stability at work. (Chopping and changing even part time work too frequently is read as a sign of flightiness.)

\section{General and professional education}

The second part of pre-work experience constitutes also the third further point of difference. The insistence of the Mexican employers that applicants be capable of doing jobs without training seems to have influenced the orientation and content of sections of scholastic education. In 1975, there were some 8,000 private junior secondary schools (which offer the seventh, eighth and ninth years of schooling), strongly geared to 
business, commerce and industry. Much more striking is the composition of university education. Since it is virtually the final stage of education open to relatively large numbers of people, almost all university students must expect to enter full time employment upon graduation. That is true of course for the university students of Ghana and Sri Lanka also. But whereas in 1975 these countries had most of their students enrolled in arts and humanities, the National University of Mexico, UNAM, had a mere 7 per cent so registered. The remaining 93 per cent were studying engineering, administration, business, accountancy and similar occupationally focused subjects. The students were enabled to seek part time jobs related to their studies and so convince prospective employers that by both paper qualification and work experience they could undertake work with no further training. Similarly, the employer who worked out a career scheme for salesmen stipulated that, for promotion to manager, they would need a degree in business administration.

In contrast, the employers of Ghana and Sri Lanka were still content to specify simply a university degree of any kind for many jobs, on the assumption that the actual job training would be done within full time employment.

Amount of education and quality of performance A final point of difference derived from colonial experience is that, in both Ghana and Sri Lanka, employers take note not only of the level of education attained by an applicant, but also of the quality of his performance. For example, at the end of secondary schooling, both countries hold leaving and selection examinations of the Ordinary or ' $O$ ' level. As these are set and marked by a central organisation, a standard measure of performance is taken and students are graded according to Distinctions, Credits and Passes. (The system is obviously British.) Since there is a standard measure, employers tend to specify their MEQLs in terms of a number of subiects, of which some-especially English and Mathematics-have to be Credits-and, in Sri Lanka, to have been obtained in no more than two sittings. Employers seem to read the performance as an index of effort and application and also of general intelligence.

Mexican employers enjoy no such standard measure. Every educational institution graduates its own students and, because the Ministry of Education exercises no close supervision, in effect sets its own standards. The consequent variability is such that employers put no trust at all in the grades awarded by a school. They have helplessly to assume that the certificates they inspect do have at least minimal validity.

\section{Reasons for qualification escalation}

A point noted already as common to all three countries is that the MEQLs required for many jobs have risen in the past twenty years. What was not discussed was the reason or reasons for this, and whether the reason was identical in each country. At least six reasons might have been advanced, either singly or in combination. First, that people with higher educational qualifications might tend to be better on several counts, eg more efficient, more productive, quicker to learn, sounder in decisions, more able and willing to take initiatives, more effective in organisation. Second, that since the content of many jobs is changing and becoming more complex, better educated people would be needed to cope. Third, that, as schools expand and more people have access to education, the more able tend to move higher up the educational scale, leaving the less able with less education; the calibre of people with certificates once acceptable declines, forcing employers to seek the calibre they want among the higher certificates. Fourth, that calibre may be regarded as dependent on the quality of education: as educational opportunity widens, the quality of education tends to fall. Hence, more education and therefore higher certificates are needed to provide what used to be produced by less. Fifth, more simply, that employers take what the market offers: if people with higher qualifications are willing to do work hitherto done by people with lower qualifications at a price not much different, employers will give them that work. Sixth, that the swift production of large numbers of educated people outstrips the slower formation of modern sector jobs and forces employers to raise MEQLs to protect themselves from the press of applicants.

Reasons one, two, three and four were not adduced by many employers-although one in Mexico did suggest that, because the firm had introduced electric vacuum cleaners and polishing machines, it was appropriate that the cleaning women should have nine rather than six years of schooling. On reason one, indeed, employers tended to deny suggestions that the more educated were on average any better than their less educated colleagues-an observation borne out by their supervisors, as Angela Little's article shows.

Reason five-if the more educated are willing to do the work, let them-was mentioned by 
most of the Mexican and Ghanaian employers. Their responses seemed to suggest that the escalation of qualifications occurred almost willy nilly. People with higher qualifications begin to accommodate themselves to jobs once done by the less qualified and the employers permit it. After some time, the majority on such jobs have higher qualifications and the employers simply acknowledge the situation by raising the MEQL to fit. In Sri Lanka, where unemployment amongst educated young people has been acute for a long time, the matter had gone one stage further. Employers openly admitted that they felt compelled to raise MEQLs simply to cope with the volumes of applications.

In sum, the 70 employers did not need higher qualifications. They merely used them, either as a favour to the more highly qualified or simply to save on the costs of selection.

\section{Inferences}

Of what use are these comparisons and contrasts to people who have to decide on the allocation of resources, the development of manpower, the quantity, quality and distribution of education? Let us recall four facts:

-not one of our 70 employers had conscientiously tried to match educational attainments to job requirements;

-nearly all acknowledged that MEQLs had risen for most jobs;

-few even attempted to argue that the more educated were more efficient or more productive than the less educated;

-none had even thought of the possible wider social, educational and financial consequences of allowing MEQLs to rise.

One inference from these facts is that MEQLs are much more a function of the supply of various educational levels and the state of employment opportunities than of ascertained need for certain levels of scholastic attainment for given ranges of jobs and careers. A second inference might be that governments are being pushed into expenditures which are not only unnecessary-hence wasteful-but actually inequitable and regressive. If that inference is made, it leads to a minimal third inference, namely, that governments, being major employers themselves, should re-examine the bases of their own practices for setting MEQLs. They might commission tests to deter- mine precisely what education is really needed for their jobs and careers.

They might consider, too, whether there are alternatives to the school and university for developing manpower. The Mexican employers seem to have succeeded in inducing a custom of study-with-work as a condition of employment. Could employers with internal labour markets, like the governments of Ghana and Sri Lanka, create more comprehensive patterns of studywith-work, so that a path from office boy to permanent secretary could be trodden by the average, and not simply by the exceptional? Such a pattern of career development might even be considered for the vast sectors of family and self employment. It might necessitate a diversion of resources from secondary and tertiary schooling, but it might develop manpower more productively.

\section{References}

Agyeman, K. et al, forthcoming, 'Qualifications and Employment in Ghana', IDS Research Reports 3, IDS, Sussex

Brooke, N.' et al, 1978, 'Qualifications and Employment in Mexico', IDS Research Reports 1, IDS, Sussex

Deraniyagala, C. et al, 'Qualifications and Employment in Sri Lanka', IDS Research Reports 2, IDS, Sussex 